\title{
De Buster Brown a Burroughs: introdução a uma genealogia irônica dos quadrinhos brasileiros*
}

\author{
Alexander Linck Vargas* \\ Nos rendez-vous os defluxos são grátis \\ Sébastien Auguste Sisson
}

\begin{abstract}
Uma genealogia dos quadrinhos brasileiros teria que necessariamente começar com uma ironia. Não se trata de desdém pelo objeto. Pelo contrário. A ironia diz respeito a contradições que não se resolvem. Deste modo, reinveste a atenção, contorcendo identidades, articulando territórios distintos, opostos, não na direção de uma síntese, mas de uma tensão não resoluta que ainda assim é plástica, tem sua forma fluída. Ironicamente, então, defender-se-á que a contraparte mítica de As aventuras de Nhô Quim ou impressões de uma viagem à corte (1869), supostamente a primeira história em quadrinhos (HQ) do Brasil, é Chiquinho, ou antes, Buster Brown (1902-1921), personagem de Richard F. Outcault, decalcado na revista O tico-tico (1905-1962) e posteriormente produzido por artistas como Luis Gomes Loureiro, Augusto Rocha, Alfredo Storni, Paulo Affonso, Osvaldo Storni, Miguel Hochman (Moya, 1986; Cirne, 1990; Azevedo, 2005; Vergueiro, 2017).
\end{abstract}

A origem dos quadrinhos brasileiros é uma invenção. Nietzsche (apud FouCAULT, 2003) já acusava, contra a imponência e solene ocasião da origem, a artimanha, os segredos sujos e vontades inconfessas da invenção. Inventar é, sobretudo, violentar o objeto, ou melhor, dar a algo a condição de objeto, e, com isso, demarcá-lo em um espaço e um tempo, de modo que o mesmo possa estar sob o sombrio escrutínio de saberes que, em última instância, buscam saciar maneiras de poder. Esse paradigma, tão caro ao método científico, revela-se igualmente ficcional, no sentido em que produz fictos para apagar seus próprios rastros e disfarçar a circularidade do pensamento investido de vontade. Isso cabe perfeitamente ao mito de Angelo Agostini como precursor dos quadrinhos. De maneira objetiva - e assim obediente ainda ao modelo da origem -, sabe-se que, pelos mesmos critérios estéticos que elegeram Agostini, Sebastien Auguste Sisson seria, com Na-

\footnotetext{
O presente trabalho foi realizado com apoio da Coordenação de Aperfeiçoamento de Pessoal de Nível Superior - Brasil (CAPES) - Código de Financiamento oo1.

* Doutor em Literatura pela Universidade Federal de Santa Catarina (UFSC) e professor na Universidade do Sul de Santa Catarina (Unisul). E-mail: linck.alexandre@gmail.com.
} 
moro, quadros ao vivo, publicado em 15 de outubro de 1855 na Brasil Illustrado, o então progenitor da HQ nacional. O pioneirismo de Agostini, uma invenção, mais especificamente dos anos 1980, foi capitalizado pela Associação dos Quadrinhistas e Caricaturistas do estado de São Paulo (AQC-ESP), de 1984. Organizada pela defesa do "projeto de lei do Deputado Federal Jorge Paulo (PDT) que propunha que as editoras e jornais publicassem $50 \%$ de seu material de quadrinhos de autores nacionais" (SouzA, s.d.), a AQC era também de uma resposta à polêmica ocasionada por um grupo de intelectuais da Academia Brasileira de Letras que propusera uma homenagem a Adolpho Aizen, defendendo a data de 14 de março como o Dia das Histórias em Quadrinhos, em homenagem aos cinquenta anos do Suplemento Juvenil, publicação de 1934 fortemente associada à invasão dos quadrinhos norte-americanos (Gomes, s.d.).

Por resultado, em 1985, a AQC criaria o prêmio Angelo Agostini e conseguiria oficializar o Dia do Quadrinho Nacional, 30 de janeiro, data de lançamento de As aventuras de Nhô Quim (NALIATO, 2016). É importante acrescentar o momento histórico da redemocratização do Brasil. Conscientemente ou não, Agostini, um ferino abolicionista e republicano, adequar-se-ia muito melhor aos anseios da AQC do que Sisson, nomeado litógrafo imperial e cavaleiro pela Imperial Ordem da Rosa (Gomes, s.d.; CAMPos, 2015).

Contudo, evocar Sisson serve-nos somente a título de breve ironia. Afinal, girar sobre quem seria o autêntico pioneiro dos quadrinhos é ainda buscar o lugar de origem perdido, acusar a mentira em nome de uma verdade que faz esquecer o jogo de forças que a oportuniza, pois tanto Agostini quanto Sisson dependem de considerável dose de interesse para que sejam considerados (proto)quadrinistas. Cirne (1990) diferenciaria quadrinístico de quadrinizante. Enquanto aquele corresponde a uma linguagem, este guarda uma potência na medida em que faz relações semioticamente. É possível aprofundar a vontade quadrinizante a partir da sociologia da arte, considerando que o que é ou não quadrinhos depende menos de uma essência - ou uma linguagem - e mais de uma perpétua negociação entre agentes que traçarão a validade de critério e arbitrária presença ou ausência de determinada obra (BEATY, 2012).

Deste modo, quadrinístico é aquilo que opera um movimento centrípeto em direção à convenção, esta, também móvel. É a obra que reúne modos de ser material e é estética o suficiente para tornar-se praticamente impossível de ser afastada daquilo que se convencionou chamar por quadrinhos. Já quadrinizante é o que está à margem, à espera de uma captura que pode ou não acontecer conforme a convenção se move. Nota-se, porém, que há uma estrita dinâmica: a periferia é a condição possível de delimitação do centro, i.e., os quadrinhos conseguem reafirmar sua identidade essencial ao vislumbrarem o seu próprio fim, ao anteverem os não quadrinhos, aquilo que força o convencional ao avesso.

É por essa região limítrofe que os denominados quadrinhos experimentais trilham. Consideremos Baiacu (2017), editado por Angeli e Laerte, dois grandes no- 
mes dos quadrinhos que remetem respectivamente às revistas Chiclete com banana (1985-1990) e Piratas do Tietê (1990-1992). Ao oportunizarem o contágio entre quadrinhos e literatura, poesia, fotografia, livro ilustrado e charge, fazem com que obras indefinidas possam ser entendidas enquanto quadrinhos, algo pouco provável caso as mesmas fossem publicadas em outro contexto.

É o caso do trabalho de Laura Lannes: com desenho minimalista, cores carregadas, grandes vazios, sentenças curtas e esparsas, misto de técnicas de pintura, a história retrata as andanças da própria autora vindo a ser um fantasma na percepção dos colegas na Casa do Sol, residência artística de onde a Baiacu saiu. Das suas dezessete páginas, apenas uma possui imagens quadrinizadas. De resto, prevalece a poética de um livro ilustrado, com a equivalência de uma ilustração por página, única ou dupla, na maioria das vezes acompanhada de texto. É possível negar o status de quadrinhos à obra de Lannes, inclusive a despeito da página que os traz expressamente, porém, isso faria com que outras obras, tão problemáticas e distintas quanto, fossem igualmente exiladas, de Soft city (1969-1975), de Pushwagner, a Poema em quadrinhos (1969), de Dino Buzzati, de The cage (1975), de Martin Vaughn-James, a Superman 75 vol. 2 - a morte do Superman (1993), de Dan Jurgens.

O que a observação da vontade quadrinizante e a experiência a que Baiacu se associa devem nos atentar é menos à busca por respostas à exaurida pergunta: "o que afinal são os quadrinhos", feita rotineiramente desde os anos 1970 (GroensteEn, 2015), e mais à manifestação da vontade e mudança por contato. Existe uma subjetividade a ser considerada e esta parece operar por fora de qualquer regime identitário. Mais importante do que os quadrinhos são para aquele que o percebe, a linha de fuga que eles constantemente traçam. Retomemos o caso de Chiquinho. Chamá-lo de contraparte mítica implica acusar a impureza que falta à historiografia dos quadrinhos brasileiros. Agostini precursor dos quadrinhos brasileiros é um mito por deveras apolíneo; restitui o sonho da nação (abolição da escravatura, proclamação da República, nacionalização dos quadrinhos, redemocratização), de modo a instituir um estado de formas (o que os quadrinhos são, onde eles começam e têm sua raiz, instituindo um modelo de representação que regula ramificações que lhe são estranhas).

Muito diferente é o que Chiquinho potencializa. Primeiramente porque não é uma pessoa mítica, mas um coletivo, em boa parte anônimo. Após o fim das tiras de Buster Brown nos Estados Unidos, no início dos anos 1920, a produção brasileira não cessou, e Chiquinho permaneceu presente até o fim de $O$ tico-tico nos anos 1960. Atesta-se a crescente importância do personagem nos anos iniciais da revista pela edição número 15, de 17 de janeiro de 1906, na qual o editor justifica a ausência de Chiquinho por ele estar de castigo (O тісо-тісо, 1905-1961). Porém, desde a primeira edição de $O$ tico-tico, Chiquinho já surge apropriado por um artista que 
visivelmente não é Outcault. ${ }^{1}$ No Brasil, o cachorro Tige ganha o nome peculiar de Jagunço, e Luis Loureiro é quem cria o menino negro Benjamin:

Durante a Primeira Guerra Mundial, O tico-tico praticamente não recebia material estrangeiro, cabendo a Loureiro a autoria de histórias inéditas para o personagem, inclusive alterando a sua personalidade. $\mathrm{O}$ nosso Chiquinho era uma criança brincalhona, alegre e divertida, diferente de Buster Brown, que era um exemplo negativo de comportamento. O Chiquinho original, do jornal americano New York Herald, foi bem abrasileirado, mérito de Luis Loureiro, a ponto de abandonar seu chapéu e aquela roupa de marinheiro, pouco adequada para o clima tropical (AzEvedo, 2005, p. 21-22).

Garoto de beleza germânica, família burguesa e trajando originalmente terninho de marinheiro, Chiquinho destaca-se por suas peraltices, sendo por vezes punido. Em sua primeira aparição em $O$ Tico-Tico empunha um chicote e corre atrás de Jagunço, ocasionando a queda de sua irmã bebê, da irmã mais velha e de sua mãe, para o desespero da empregada e do jardineiro que correm para acudi-los. Por fim, acaba apanhando do pai, fazendo da HQ uma versão mais branda, porém com a mesma moral educativa-punitivista, de Max und Moritz (1865), de Wilhelm Busch, traduzido para fuca e Chico no Brasil.

Diferentemente da posição ocupada por Agostini, Chiquinho não é o paradigma dos quadrinhos, pelo contrário, é uma HQ ordinária em estrutura, temática ou desenho. Contudo, vibra a partir de uma indistinção (Buster Brown/Chiquinho) que se orienta por um princípio de individuação abalado (função autor) e que extasia, sai de si, perante o outro benquisto (diante da imagem de um menino aburguesado norte-americano). Se aqui se insinua um dualismo mítico entre Apolo e Dionísio à maneira de Nietzsche (2007), o mesmo só pode ser mais uma vez considerado ironicamente. Chiquinho não é mito algum. Está mais para um contramito, o mito que desativa o mito, pois o que fica evidente é uma condição patética que atravessará os quadrinhos brasileiros desde sempre, a despeito de qualquer narratofilia identitária, locus de origem vertical. Seja nos quadrinhos de super-herói, de terror, eróticos ou mesmo nos chamados alternativos.

Em cada gênero ou estilo nota-se que a quadrinhografia brasileira durante o século XX assimila de maneira escrachada o corpo do outro. Inclusive a personagem nacional mais ilustre, Mônica (1963), de Mauricio de Sousa, é uma deglutição de Luluzinha e a coadjuvante Aninha, e Cebolinha guarda semelhanças que vão além do nome com o Bolinha, todos personagens da tira Little Lulu (1935), de Marge. Não se trata, porém, de delatar um plágio, como fizera a Primeira exposição internacional de Histórias em Quadrinhos, de 1951, em São Paulo (Moya, 2001), pois o

\footnotetext{
Segundo Azevedo (2005, p. 18), "no início coube a Renato de Castro, editor da revista [O TicoTico], o decalque de Buster Brown”. Porém, a primeira história é assinada por um nome diferente. Semelhante a Mary [ilegível] (O Tico-TICO, 1905-1961).
} 
que se percebe não é uma cópia deslavada, mas um criativo procedimento que leva o eu ao encontro do outro, ou antes, um ante-eu, protossubjetividade que se heterogeneiza na captação por incorporação. Em outras palavras, aos quadrinhos brasileiros prevaleceu uma subjetividade que poderíamos chamar de antropofágica:

Estendido para o domínio da subjetividade, o princípio antropofágico poderia ser assim descrito: engolir o outro, sobretudo o outro admirado, de forma que partículas do universo desse outro se misturem às que já povoam a subjetividade do antropófago e, na invisível química dessa mistura, se produza uma verdadeira transmutação. Constituídos por esse princípio, os brasileiros seriam, em última instância, aquilo que os separa incessantemente de si mesmos. Em suma, a antropofagia é todo o contrário de uma imagem identitária (RoLNIK, 200o, p. 452-453).

Nunca fora intuito do Manifesto Antropófago (1928), de Oswald de Andrade, circunscrever a antropofagia a uma brasilidade: "Única lei do mundo. Expressão mascarada de todos os individualismos, de todos os coletivismos. De todas as religiões. De todos os tratados de paz" (ANDRADE, 2009, p. 504). Inclusive, é da antropofagia cultural o apagamento, devoramento mesmo de qualquer regime identitário, dentre eles, o nacional. Contudo, como diz Suely Rolnik (200o), é uma subjetividade que pode estar mais ou menos ativa dependendo do contexto sociocultural. A condição periférica do Brasil, de colônia de exploração à nação subdesenvolvida, pode ser um fator significante. Perante um ideal, locus central do pensamento, ao qual vivências limites, formas marginais, são compulsoriamente remetidas, resultaria uma mudança por contato no seio do desejo. Isto é, conduzir a periferia ao centro, lugar privilegiado em pensamento ainda que materialmente ora negado, ocasionaria uma transformação do rosto do marginal a partir da digestão de uma falta que para ele é sempre excesso.

Poder-se-ia considerar também a epistemologia ameríndia e sua sobrevivência errática na cultura brasileira. $\mathrm{O}$ outro, subjetividade estrangeira, enreda-se em uma metafísica da predação, na qual "não há existente que não possa ser definido nos termos relacionais gerais de sua posição em uma escala relativa de potência predatória" (VIVEIROS DE CASTRO, 2015, p. 45). Dito de outro modo, uma arapuca paradigmática, que polariza a perspectiva entre predadores e presas, fazendo com que o outro que ora faz as vezes de predador pode, muito bem, sob outro ponto de vista, vir a ser a presa, e assim incorporar-se por deglutição: "Só me interessa o que não é meu" (ANDRADE, 2009, p. 504).

Uma alteridade canibal pode, portanto, por meio do contramito de Chiquinho, desatar as linhas historiográficas da cultura quadrinística brasileira. De modo que se tornaria uma tarefa porvir revisar diferentes produções para além da infeliz linha de corte que procura pioneiros de um lado e acusa plagiadores de outro, que desperta sobre o mito de origem nacional ao início do dia e empanturra-se da carnadura do estrangeiro antes de dormir. Entre as revisões mais desafiadoras estariam, então, as produções do quadrinho brasileiro contemporâneo. Consagradas 
pela crítica extracampo dos quadrinhos, prestigiadas dentro e fora do Brasil, objetos de estudo acadêmico e de valor cultural, os quadrinhos contemporâneos brasileiros reativam o ideal de originalidade, identificam uma "qualidade nacional" e afastam-se, com bastante segurança, de um passado antropofágico.

Contudo, há de se mostrar que a diferença das HQs de hoje para outrora não está no identitarismo que guarda Agostini como figura original, mas na radicalização da vontade voraz que perpassa o quadrinho brasileiro com o contramito Chiquinho. O que aconteceu nas últimas duas décadas é uma diferença de intensidade, não de natureza. O quadrinho brasileiro contemporâneo inventa-se na virada dos anos 2010. Uma série de fatores concorrem para o seu surgimento. Destacam-se, pontualmente:

- A consolidação dos grandes eventos: o Festival Internacional de Quadrinhos (FIQ) de Belo Horizonte, surgido em 1999 após o fim da Bienal Internacional de Quadrinhos e com dez edições até então; a Gibicon de Curitiba, de 2011, e renomeada como Bienal Internacional de Quadrinhos de Curitiba em 2016, com cinco edições até agora; a Comic Con Experience, de São Paulo, evento anual de cultura pop que acontece desde 2014; o Anime Friends, de São Paulo, evento de cultura japonesa que ocorre anualmente desde 2003, entre outros.

- Incentivos públicos: a inclusão das histórias em quadrinhos no Programa Nacional Biblioteca na Escola entre 2006 e 2014; o Programa de Ação Cultural (Proac) do estado de São Paulo, que contempla quadrinhos desde 2008.

- Novos meios de autopublicação: o surgimento da plataforma de crowdfunding Catarse, em 2011, que acabou se tornando um espaço bastante receptivo a projetos de quadrinhos, muitas vezes lançados nos grandes festivais.

- Novas editoras ou selos editoriais com ênfase em quadrinhos brasileiros: Zarabatana (2006), Veneta (2012), Mino (2014), entre outras, assim como o selo Quadrinhos na Cia. da editora Cia das Letras (2009).

- Lojas especializadas como ponto de encontro do cenário quadrinístico: destaque para a editora e loja Ugra, de São Paulo, que promove cursos, entrevistas e eventos, dentre eles o Ugra Zine Fest, de 2011 a 2015, reformulado e renomeado para Ugra Fest em 2017.

- Diálogo entre o mainstream e o alternativo: em 2009 é lançado MSP 50 Mauricio de Sousa por 50 Artistas, com o convite para que cinquenta artistas abordem os personagens da Turma da Mônica com alguma liberdade autoral, rompendo meio século de isolamento. O projeto acaba por ser repetido com mais duas edições nos anos seguintes. Em 2012, é lançado o lucrativo selo Graphic MSP, com histórias de traços autorais por diferentes quadrinistas brasileiros. 
- Internacionalização: publicação crescente de quadrinhos brasileiros no exterior. Em 2016, no irônico Dia do Quadrinho Nacional, Tungstênio, de Marcello Quintanilha, ganha na França, no Festival International de la Bande Dessinée d'Angoulême, o prêmio Fauve Polar SNCF, dado à melhor banda desenhada policial. Em 2018, Marcelo D'Salete, por Cumbe, ganha o prêmio de Best U.S. Edition of International Material no Eisner Award nos EUA.

- Especialização da crítica e dos estudos em quadrinhos: aumento em quantidade e qualidade de sites, blogs, canais de Youtube e colunas de jornais sobre quadrinhos; eventos acadêmicos de grande porte, destacando-se em 2011 as Jornadas Internacionais de Histórias em Quadrinhos, na Universidade de São Paulo, com sexta edição ocorrendo em 2019; crescente número de publicações teóricas sobre quadrinhos.

- Redes sociais: a visibilidade ocasionada por plataformas como Facebook (no Brasil desde 2008) e Instagram (2010) a autores, principalmente de tiras.

- Outros fatores mais amplos e diversos: a progressiva invasão dos mangás, que inclusive faria Mauricio de Sousa criar a Turma da Mônica Jovem, em 2008; a segmentação da produção e do mercado de quadrinhos; o crescimento do segmento de leitoras e autoras no cenário do quadrinho brasileiro.

Com a crise política e econômica que se arrasta no Brasil desde 2015, junto da crise das livrarias deflagrada em $2018,{ }^{2}$ entre outros fatores, o quadrinho brasileiro contemporâneo vive um refluxo. Ainda é cedo para dizer se este movimento é um lento fim ou apenas um desaceleramento momentâneo. Seja como for, a diferença de intensidade do quadrinho brasileiro contemporâneo dá a falsa ideia de uma ruptura ou uma evolução paralela àquela subjetividade antropofágica repreendida nos decalques de Buster Brown e sua vocação. Porém, o que se nota esteticamente na produção atual é a intensificação de um modo de ser que só é possível a partir de fluxos, entradas e saídas, muito mais radicalmente heterogenético, contraidentitário, devorando e incorporando não mais exclusivamente o "antropo", o homem, mas seres múltiplos de um desterritório comum.

Analisemos a HQ Burroughs, de João Pinheiro, lançada pela Veneta em 2015, e exportada para a França e Turquia, com boa repercussão. ${ }^{3}$ Parte adaptação de Naked lunch (Almoço nu, no Brasil), de William S. Burroughs, parte biografia do escritor; Pinheiro utiliza-se de grande liberdade poética para compor o protagonista a partir de um fluxo de consciência. O tom azul aliado ao estilo realista empresta à HQ a sensação de uma realidade feita à caneta esferográfica, mundo material transcrito pela necessidade de um deus compulsivo. O primeiro capítulo do quadrinho, "Vírus", começa com uma imagem do espaço sideral acompanhado da citação: "a linguagem é um vírus vindo do espaço" (Pinheiro, 2015, p. 11). Já nas

\footnotetext{
2 Para saber mais sobre a crise das livrarias, veja Batschke (2018).

3 A repercussão de Burroughs foi menor no Brasil do que na França, segundo Rogerio de Campos, editor da Veneta (CAMPOS, 2018).
} 
duas páginas seguintes, com um único quadro com a citação: "no princípio era a palavra e a palavra era Deus..." (PInHeiro, 2015, p. 12), apresenta-se um sofisticado mosaico com ladrilhos compostos de corpos celestes, nebulosas e espirais, mas também um líquido viscoso, possivelmente sangue, em virtude de uma mão empunhando uma arma de fogo que se repete e aumenta de tamanho conforme o olhar se arrasta da esquerda para a direita, de cima para baixo. Na quarta página, em mais um único quadro, com a citação: "a palavra era Deus e a palavra foi carne" (Pinheiro, 2015, p. 14), o rosto que empunha a arma é de uma caveira com um aparente chapéu mexicano; o mosaico torna-se então ainda mais borrado, destacandose o rosto de uma mulher, blocos com hieróglifos e uma máscara enegrecida.

Será somente nas páginas seguintes que seremos ambientados na Cidade do México, em seis de setembro de 1951, quando Burroughs acaba por acertar um tiro na cabeça de sua esposa Joan enquanto brincavam de William Tell. "Naquela noite, entrei em contato com o invasor. Falo sobre o impulso irracional que me moveu. [...] Possessão é como isso é chamado" (Pinheiro, 2015, p. 17). O capítulo termina em um último quadro, com o espaço ainda mais revolto e viscoso, e no centro um buraco vazio, da ferida mortal de Joan, do olhar vazio de Burroughs. Já ao final da HQ, no capítulo "A álgebra da necessidade", Burroughs sairá da boca entreaberta de Joan morta, e sua versão apequenada e envelhecida deparar-se-á consigo mais jovem logo após o assassinato: "A única coisa real sobre um escritor é o que ele escreve, e não a sua vida. [...] Sinto-me forçado à conclusão apavorante de que nunca teria me tornado um escritor sem a morte de Joan" (Pinheiro, 2015, p. 108, 109).

A América Latina é uma geografia determinante. Se a interzona, realidade intervalar, de paisagem noir e natureza viciante, é o lugar conspiratório onde William Lee se exila para escrever, a Cidade do México é, igualmente, um entremeio, sarjeta entrequadros, pela qual todo o universo passa, e com ele, a virulência da linguagem. Do espaço sideral profundo para a superfície muralizada, e, após a morte de Joan, retorno. Observa-se, então, como a Cidade do México, com a experiência muralista pós-revolucionária, é fundamental para o mundo de Burroughs. Cada capítulo, inclusive, começa com um mosaico, sobrescrito de um único símbolo no quadro central; poderia ser um muro, e também o leiaute de uma prancha de história em quadrinhos, de modo que, em ambos os casos, o que se segue com desenhos e palavras infectando os quadros são murais expandidos. Pinheiro, por vezes, trata a página como um grande quadro, ainda que dotada de pequenos quadrinhos apartados pela sarjeta.

Encontra-se também, na interzona, a reencenação de O bandido da luz vermelha (1968), de Rogério Sganzerla, com a passagem em que o mesmo homem negro é espancado pela polícia quando diz: "O mundo vai explodir! Quem tiver de sapato não sobra, não pode sobrar, não pode sobrar!” (PINHeIro, 2015, p. 84). ${ }^{4}$ Aliás, o ano de 1968 retorna em diferentes momentos pelas colagens do maio de 1968 francês,

\footnotetext{
4 No filme de Sganzerla é dito: “O terceiro mundo vai explodir!”. Pinheiro aparentemente achou melhor suprimir a territorialização terceiro-mundista.
} 
pelas referências à pop art, pela aparição de zumbis, gênero cinematográfico que se inventa em 1968 com o lançamento de Night of living dead, de George Romero, ou pela aparição da personagem Valentina, de Guido Crepax, criada em 1965, mas lançada em álbum pela primeira vez também em 1968.

$\mathrm{O}$ anacronismo de Burroughs, contudo, alastra-se para outras épocas, como o momento em que William Lee precisa refazer o gesto que causou a morte de sua esposa, acertando a testa de seus inimigos com um tiro certeiro. Nesse ponto, a HQ torna-se um videogame da virada dos anos 199o. Por fim, existe o quadrinho dentro do quadrinho, com o seguimento gráfico da EC Comics. Rolnik (2000) comenta da proximidade entre a antropofagia oswaldiana e a filosofia de Deleuze e Guattari:

Tanto em Oswald quanto em Deleuze e Guattari, temos uma crítica contundente aos modelos de subjetivação subordinados ao regime identitário e ao modelo da representação. Mas a dupla febril certamente vai mais longe nesse empreendimento, ao criar uma complexa construção conceitual para traçar efetivamente uma outra cartografia (RoLNIK, 200o, p. 453).

Burroughs, de Pinheiro, opera, nesse sentido, um curioso cruzamento. Primeiramente por antropofagizar William Burroughs. Se o fluxo de consciência quadrinizado não é estranho à poética burroughiana, com intensidade, o autor parece escoar-se nos modos de uma Água Viva, de Clarice Lispector: "As palavras brotavam feito água em mim. Eu apenas tinha que colocar aquela água para fora no ato de escrita" (Pinheiro, 2015, p. 59). Burroughs não é um personagem-sujeito claro, não constitui uma identidade. É discutível chamar o quadrinho de biografia; questionável classificá-lo como adaptação. Mesmo assim, Pinheiro escreve a vida de uma heterosubjetividade e anacroniza Naked lunch traduzido para uma temporalidade turbulenta: ${ }^{5}$

Trata-se de estar atento às rachaduras das formas vigentes no atual, para escutar o burburinho das singularidades pré-individuais ou protosubjetivas que se agitam no virtual corpo sem órgãos; trata-se igualmente de farejar a pista de agenciamentos que favoreçam a atualização de tais singularidades como matérias de expressão. E, assim, infinitamente (RolNIK, 200o. p. 458).

Pinheiro devora Burroughs e este leva a antropofagia até as últimas consequências, consumindo febrilmente a si mesmo. Não mais uma simples deglutição de outro sujeito, mas canibalização da própria identidade especular, do sujeito ideal projetado na tenra infância pelo estádio do espelho lacaniano (1998). Duas maneiras conduzem a essa ruptura; a primeira é ocasionando infinitas rachaduras

5 Conforme Pinheiro, Burroughs foi desenhado durante as jornadas de junho de 2013 (Pinheiro, 2019). 
na (auto)imagem identitária, isto é, sarjetas no grande quadro, multiplicando a si mesmo: "quando um espelho se quebra em dez partes, em cada um desses fragmentos reencontrar-se-á a imagem inteira e não despedaçada. E em cada uma das partes do espelho quebrado a imagem não será menor do que no espelho inteiro" (Coccia, 2010 p. 26).

Daí uma subjetividade-Burroughs poder "refletir" sobre murais mexicanos, jogos eletrônicos, movimentos sessentistas, labirintos noir. Contudo, o segundo modo, ainda mais radical de ruptura identitária, é a ética do junkie, que engole a sangue os cacos de vidro do espelho, os incorpora a duras custas, overdose. Devora-te a ti mesmo. Pelo consumo da imagem de si, a figura desmancha-se: o universo abre e fecha como uma boca cheia mastigando, a transa com um rapaz termina em uma forma aberrante com um ânus na cabeça, o cadáver da esposa torna-se a bocarra da vida do pequeno escritor, e as singularidades multiplicadas transbordam, reconfiguram-se em cut-ups intensivos da matéria:

Possessão esquizofrênica, espaços onde não existe vida, cristais de ranho, esterco inodoro, carne morta, sangue negro, um viciado que perdeu cinco quilos em um minuto, mutações, um cu que deixa o Louvre humilhado, cagalhões, bichas elegantes, putas decadentes, yuppies filhos de uma puta, gângsters, michês, saxofonistas viciados, hipsters, artistas, dançarinas, moscas de bar, escritores, jogadores de sinuca e apostadores, mendigos e salteadores, um fogo que ninguém é capaz de apagar, sarjetas do mundo, chuva de fuligem, sexo, drogas de todos os tipos, urubus bicando as ruas enlameadas, políticos corruptos, médicos charlatões (PinHeiro, 2015, p. 69).

Eis aqui o segundo aspecto da oportuna intersecção do quadrinho de Pinheiro: o texto "The Impasses Of Control" (Os limites do controle), que na HQ é o relatório produzido por Burroughs (agente Bill Lee), foi proferido no colóquio Schizo Culture, realizado na universidade de Columbia em novembro de 1975, e que contava com a presença de filósofos franceses, como Foucault, Lyotard, Guattari e Deleuze; e artistas de vanguarda, como Kathy Acker, Richard Foreman, John Giorno, John Cage e o próprio Burroughs. A conferência de Burroughs ganhou especial interesse de Deleuze que adotaria o conceito de controle em um pequeno, porém bastante influente artigo, Post-scriptum sobre as sociedades de controle, de 1990. Todavia, a poética burroughiana já era de grande sintonia com as ideias de Deleuze e seu parceiro Guattari desde $O$ anti-Édipo (1972). A premissa linguagem-vírus dialoga com ideias recorrentes na filosofia deleuzeana. O contágio ocasionado pelos devires é um tópico à parte. Um devir é um bloco aparalelo de dupla captura, linha de fuga dos seres, aliança: "Se a evolução comporta verdadeiros devires, é no vasto domínio das simbioses que coloca em jogo seres de escalas e reinos inteiramente diferentes, sem qualquer filiação possível” (Deleuze; Guattari, 2012b, p. 19).

Burroughs sentiu-se possuído quando da morte de Joan; era como se algo viesse ao seu encontro e ele, rápido como uma bala, dirigisse-se a isso. Ele ainda era ele, 
havia um "ele", mas também consistia, em fuga, um vir-a-ser: "O mal nasceu ali" (PInHeIro, 2015, p. 19). Resulta, então, a estranha receita do monstruoso Doutor Benway: "Você sofre de uma disfunção simbólica, Sr. Lee. As palavras são o cerne de sua patologia. [...] Escrever é a única maneira de esconjurar esse verme que o invadiu pelo cu ou, seja lá por onde foi. [...] É a linguagem que constitui aquilo que consideramos a realidade" (Pinheiro, 2015, p. 30-31).

Se a linguagem é um vírus vindo do espaço, imagina-se, como um bom sanitarista, que a melhor coisa a se fazer é afastar-se da língua. Mas a recomendação é justamente a contrária: ela dobra a aposta, afinal, a linguagem constitui a realidade. Então o que resta fazer, como resistir? A única saída possível, escrever, implica não sucumbir ao mal do vírus, porém elaborar contra ele "uma espécie de língua estrangeira, que não é uma outra língua, nem um dialeto regional redescoberto, mas um devir-outro da língua, uma minoração dessa língua maior, um delírio que a arrasta, uma linha de feitiçaria que foge ao sistema dominante" (Deleuze, 1997, p. 16). Daí a importância de cortar a filiação divina da língua, de menorizá-la em uma aliança profana com a vida à sarjeta. Reconhecimento que Burroughs tem, ao fim do quadrinho, perante o pequeno escritor saído da boca de Joan, do universo que se abriu a ele, desterritório poético e vital ao qual ele se lançou. "Contra o mundo reversível e as idéias objetivadas. Cadaverizadas. O stop do pensamento que é dinâmico. O indivíduo vítima do sistema. Fonte das injustiças clássicas. Das injustiças românticas. E o esquecimento das conquistas interiores" (ANDRADE, 2009. p. 506). Burroughs, então, converte-se um corpo sem órgãos $(\mathrm{CsO})$, conceito que Deleuze e Guattari tomam emprestado de Antonin Artaud:

O CsO é feito de tal maneira que ele só pode ser ocupado, povoado por intensidades. Somente as intensidades passam e circulam. Mas o $\mathrm{CsO}$ não é uma cena, um lugar, nem mesmo um suporte onde aconteceria algo.[...] Ele é a matéria intensa e não formada, não estratificada, a matriz intensiva, a intensidade $=0$, mas nada há de negativo neste zero, não existem intensidades negativas nem contrárias. Matéria igual a energia. Produção do real como grandeza intensiva a partir do zero (Deleuze; GuATTARI, 2012a, p. 16).

Pensar Burroughs como um corpo sem órgãos não significa apagar o seu registro por completo. Grandeza intensiva a partir do zero implica a virtualidade criadora na qual mobilizam-se proto-subjetividades, pré-indivíduos, do spatium de onde devêm agentes e mugwumps - ainda que estes se degladiem em uma identidade alquebrada. A sociedade do controle de que fala Burroughs-Deleuze (1992) é essencialmente a sociedade da identidade, na qual os indivíduos estão cheios de concessões, mas ninguém mais come ninguém, não há predação porque todos são identificados, rotulados, interpretados. Não há necessidade de comer, nem rota de fuga de si. Apenas uma distopia identitária. Contra isso, não se trata de exterminar os organismos, mas desobstruir as intensidades: 
É necessário guardar o suficiente do organismo para que ele se recomponha a cada aurora; pequenas provisões de significância e de interpretação, é também necessário conservar, inclusive para opô-las a seu próprio sistema, [...]; e pequenas rações de subjetividade, é preciso conservar suficientemente para poder responder à realidade dominante. Imitem os estratos. Não se atinge o $\mathrm{CsO}$ e seu plano de consistência desestratificando grosseiramente (Deleuze; GuatTARI, 2012a, p. 26).

Foi enquanto organismo residual que o contramito de Chiquinho nos serviu ironicamente até agora. Não se trata de tecer filiações a partir de Buster Brown, com Burroughs de João Pinheiro enquanto um dos herdeiros legítimos, mas atentar para um espaço móvel e mobilizante de intensidades que não prestam, ou não precisam prestar, contas a um regime identitário. "O CsO é desejo, e ele e por ele que se deseja. [...]. O desejo vai até aí: às vezes desejar seu próprio aniquilamento, às vezes desejar aquilo que tem o poder de aniquilar" (Deleuze; GuATtARI, 2012a, p. 32). Uma genealogia dos quadrinhos brasileiros, portanto, não seria possível sem a aniquilação inerente ao intenso desejo de uma identidade. Eis o segredinho sujo de sua invenção: o quadrinho brasileiro deseja identidades a ponto de destruir e destrói-as porque sempre desejou outras coisas.

Poder-se-ia contra-argumentar que Burroughs é um caso tão exato que se torna inadequado. Afinal, por suas características, dirão aqueles que desejam reidentificá-lo, é uma obra bastante propícia a estabelecer alianças com Chiquinho, assim como costurar a subjetividade maquínica deleuzeana-guattariana, subjetividade não dada, resultado de uma "produção que transborda o indivíduo por todos os lados" (RolNKI, 200o, p. 453), e a subjetividade antropofágica oswaldiana, alteridade canibal, contraimagem identitária em um devir-outro.

Contudo, o quadrinho brasileiro contemporâneo abunda de subjetividades radicalmente contraidentitárias. Os devires-animal em Lavagem (2015), de Shiko (devir-porco), Klaus (2014), de Felipe Nunes (devir-tigre), Castanha do Pará (2016), de Gidalti Jr. (devir-urubu), e Apocalipse, por favor (2015), de Felipe Parucci (devir-lobo, devir-gaivota); os devires-negro em Angola fanga (2017), de Marcelo D'Salete, e Deus essa gostosa (2014), de Rafael Campos Rocha; os devires-coisa em A vida de fonas (2014), de Magno Costa e Marcelo Costa; os devires-outro em Mensur (2017), de Rafael Coutinho. A predação do super-herói em Contos dos orixás (2018), de Hugo Canuto, e do K-Pop em Roly poly (2018), de Daniel Semanas; os corpos simbióticos em Manual do minotauro (2008), de Laerte, Hermínia (2015), de Diego Sanchez, e Topografias (2016), de Bárbara Malagoli, Julia Balthazar, Lovelove6, Mariana Paraizo, Paula Puiupo e Taís Koshino; o organismo esvaziado nas tirinhas de André Dahmer, Ricardo Coimbra e Bruno Maron; o cromatismo intensivo em Aventuras na Ilha do Tesouro (2014), de Pedro Cobiaco; os seres sensíveis que antecedem as opiniões em Bulldogma (2016), de Wagner William; uma língua menor por toda a obra de Marcello Quintanilha; os perceptos e afetos desterritorializados em Eles estão por aí (2018), de Bianca Pinheiro e Greg Stella. 
Outros tantos quadrinhos e quadrinistas poderiam ser citados e tratados com a mesma profundidade e rigor. Se até aqui não foram é porque Burroughs, de João Pinheiro, foi o acontecimento mais irônico.

\section{Referências}

Andrade, Oswald. Manifesto antropófago. In. Telles, Gilberto Mendonça. Vanguarda européia e modernismo brasileiro: apresentação dos principais poemas metalinguísticos, manifestos, prefácios e conferências vanguardistas, de 1857 a 1972. Petrópolis: Vozes, 2009.

Angeli; Laerte (ed.). Baiacu. São Paulo: Todavia, 2017.

Azevedo, Ezequiel de. O Tico-Tico: cem anos de revista. São Paulo: Via Lettera, 2005.

BATSCHKE, Nayara. Exame: Crise nas livrarias Cultura e Saraiva abala o cenário editorial no Brasil. 2018. Disponível em: https://exame.abril.com.br/economia/crisenas-livrarias-cultura-e-saraiva-abala-o-cenario-editorial-no-brasil/. Acesso em: 30 abr. 2019.

BEATy, Bart. Comics versus art. Toronto: University of Toronto, 2012.

Burroughs, William S. Os limites do controle. In. Pinheiro, foão. Burroughs. São Paulo: Veneta, 2015.

Burroughs, William S. Almoço nu. São Paulo: Cia das Letras, 2016.

CAmpos, Rogério de. Imageria: o nascimento das histórias em quadrinhos. São Paulo: Veneta, 2015.

Campos, Rogério de. Entrevista na Editora Veneta. São Paulo, 2018.

Cirne, Moacy. História e crítica dos quadrinhos brasileiros. Rio de Janeiro: Europa; Funarte, 1990.

Coccia, Emanuele. A vida sensivvel. Florianópolis: Cultura e Barbárie, 2010.

Deleuze, Gilles. Crítica e clínica. São Paulo: 34, 1997.

Deleuze, Gilles. Post-scriptum sobre as sociedades de controle. In. Conversações. São Paulo: Editora 34, 1992.

Deleuze, Gilles; Guattari, Félix. Mil platôs: capitalismo e esquizofrenia. vol. 3. São Paulo: 34, 2012a.

Deleuze, Gilles; Guattari, Félix. Mil platôs: capitalismo e esquizofrenia. vol. 4 . São Paulo: 34, 2012b.

Família Sisson: Sébastien Auguste Sisson. 2008. Disponível em: https: //familiasisson.wordpress.com/biografias/a-historia/. Acesso em: 30 abr. 2019. 
Foucault, Michel. A verdade e as formas jurídicas. 3. ed. Rio de Janeiro: Nau, 2003.

Gomes, Ivan Lima. Angelo Agostini e os quadrinhos: algumas questões. Submetido à publicação. [s.d].

Groensteen, Thierry. O sistema dos quadrinhos. Nova Iguaçu: Marsupial, 2015.

LACAN, Jacques. O estádio do espelho como formador da função do eu. In. Escritos. Rio de Janeiro: Zahar, 1998.

Moya, Álvaro de. Anos 50, 50 anos: edição comemorativa da primeira exposição internacional de Histórias em Quadrinhos. São Paulo: Opera Graphica, 2001.

Moya, Álvaro de. História das histórias em quadrinhos. Porto Alegre: L\&PM, 1986.

NAliato, Samir. Universo HQ: Dia do Quadrinho Nacional ou Dia Nacional dos Quadrinhos? 2016. Disponível em: http://www.universohq.com/universoparalelo/dia-do-quadrinho-nacional-ou-dia-nacional-dos-quadrinhos/. Acesso em: 30 abr. 2019 .

Nietzsche, Friedrich. O nascimento da tragédia. São Paulo: Cia. das Letras, 2007.

O Tico-Tico: Jornal das crianças. Rio de Janeiro, 1905-1961. Disponível em: http: //hemerotecadigital.bn.br/acervo-digital/tico-tico/153079. Acesso em: 30 abr. 2019.

Pinheiro, João. Burroughs. São Paulo: Veneta, 2015.

Pinheiro, João (João Pinheiro). Comentário sobre resenha sobre HQ Burroughs. São Paulo, 18 abr. 2019. Facebook: joaoppinheiro. Disponível em: https://www.facebook.com/joaoppinheiro/posts/10205358413515589?comment_ tracking $={ }_{7} \mathrm{~B} \% 22 \operatorname{tn} \% 22 \% 3 \mathrm{~A} \% 22 \mathrm{O} \% 22 \% 7 \mathrm{D}$. Acesso em: $30 \mathrm{abr}$. 2019.

Rolnik, Suely. Esquizoanálise e antropofagia. In. Allıez, Éric. (Org.). Gilles Deleuze: uma vida filosófica. São Paulo: Editora 34, 2000.

SouzA, Worney Almeida de. AQC-ESP: Quem Somos. [s.d.]. Disponível em: http: //aqcsp.blogspot.com/p/quem-somos.html. Acesso em: 30 abr. 2019.

Vergueiro, Waldomiro. Panorama das histórias em quadrinhos no Brasil. São Paulo: Peirópolis, 2017.

Viveiros De Castro, Eduardo. Metafísicas canibais: elementos para uma antropologia pós-estrutural. São Paulo: Cosac Naify, 2015.

Recebido em 30 de abril de 2019.

Aprovado em 20 de outubro de 2019. 


\title{
Resumo/Abstract/Resumen
}

De Buster Brown a Burroughs: introdução a uma genealogia irônica dos quadrinhos brasileiros

\begin{abstract}
Alexander Linck Vargas
O presente artigo busca fazer uma genealogia irônica do quadrinho brasileiro a partir do questionamento de sua origem e da invenção do contramito Chiquinho, isto é, Buster Brown, personagem criado por Richard F. Outcault e predado pela revista brasileira $O$ Tico-Tico. Diferentemente de um regime identitário, observarse-á na experiência dos quadrinhos do Brasil uma subjetividade antropofágica (Oswald de Andrade), ou antes, uma grandeza intensiva protossubjetiva e préindividual, corpo sem órgãos (Deleuze, Guattari). Procurando atestar a hipótese, a análise irá se deter no quadrinho brasileiro contemporâneo, mais especificamente em Burroughs, de João Pinheiro. Com isso, espera-se contribuir para uma historiografia contraidentitária das histórias em quadrinhos brasileiras.
\end{abstract}

Palavras-chave: genealogia, quadrinhos brasileiros, identidade, antropofagia, corpo sem órgãos.

From Buster Brown to Burroughs: introduction to an ironic genealogy of Brazilian comics

\section{Alexander Linck Vargas}

This article seeks to make an ironic genealogy of Brazilian comics starting from questioning their origin and the invention of Chiquinho, the counterfeit Buster Brown, a character created by Richard F. Outcault and predated by the Brazilian magazine $O$ Tico-Tico. In contrast to an identity regime, an anthropomorphic subjectivity (Oswald de Andrade), or rather, an intense proto-subjective and preindividual, body without organs (Deleuze, Guattari), will be observed in Brazilian comics. In order to test the hypothesis, the analysis will focus on the contemporary Brazilian comic, specifically on Burroughs, by João Pinheiro. With this, it is expected to contribute to a counter-identitarian historiography of Brazilian comics.

Keywords: genealogy, Brazilian comics, identity, anthropophagy, body without organs.

De Buster Brown a Burroughs: introducción a una genealogía irónica de los cómics brasileños

\section{Alexander Linck Vargas}

Este artículo busca construir una genealogía irónica del cómic brasileño a partir del cuestionamiento de su origen y de la invención del contramito Chiquinho, es decir, Buster Brown, personaje creado por Richard F. Outcault y predado por la revista brasileña $O$ Tico-Tico. A diferencia de un régimen identitario, se observará 
en la experiencia de los cómics de Brasil una subjetividad antropofágica (Oswald de Andrade), o antes, una grandeza intensiva protosubjetiva y preindividual, cuerpo sin órganos (Deleuze, Guattari). En busca de la hipótesis, el análisis se detendrá en el cómico brasileño contemporáneo, más específicamente en Burroughs, de João Pinheiro. Con ello se espera contribuir a una historiografía contraidentitaria del cómic brasileño.

Palabras clave: genealogía, cómic brasileño, identidad, antropofagia, cuerpo sin órganos. 